\title{
A Novel Crosslinked Hyaluronic Acid Nanogel for Drug Delivery
}

\author{
Sílvia Santos Pedrosa, Catarina Gonçalves, Laurent David, Miguel Gama*
}

An amphiphilic hyaluronic acid conjugate is successfully developed based on grafting a thiolated hydrophobic molecule to the polysaccharide backbone. The engineered conjugate is capable of assembling into nanostructures once dispersed in water, with average diameter of $80.2 \pm 0.4 \mathrm{~nm}(n=5)$, stable up to 6 months. The thiolated HyA conjugate is reticulated by dissulfide bond with a homofunctional crosslinker-1,4-Bis(3-[2-pyridyldithio]propionamido)butane (DPDPB). The drug loading efficiency of the reticulated and non-reticulated nanogel is accessed with two hydrophobic drugs, curcumin and simvastatin. Results suggest that crosslinked nanogel exhibit higher stability upon dilution and drug loading efficiency and proves to be a redox sensitive material. The nanogels hold great potential as stealth carriers of lipophilic drugs.

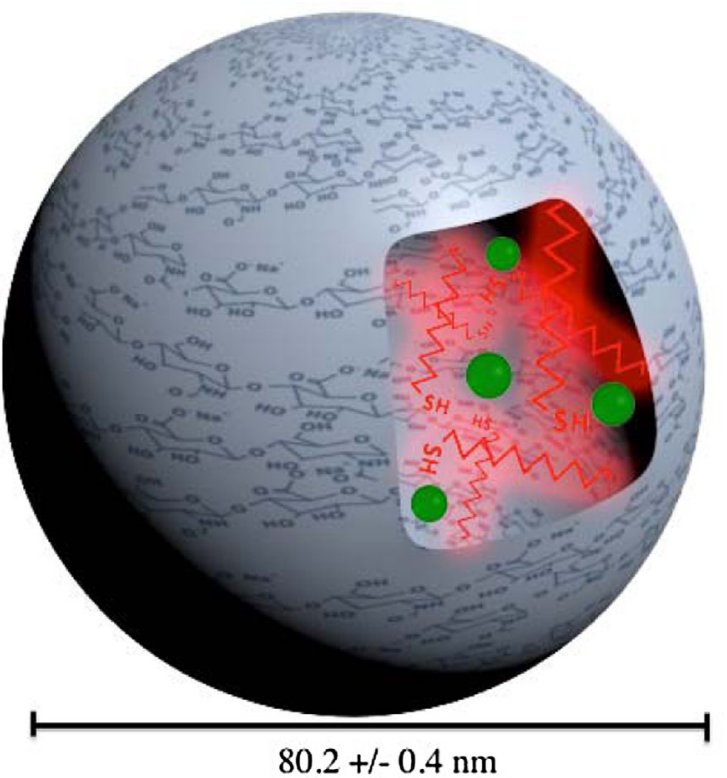

\section{Introduction}

Polymeric nanogels are a class of nanocarrier systems based on biodegradable polymers that can be applied in drug sustained release. These systems display prolonged blood circulation time, enhanced drug solubility and selective accumulation at tumour tissues by enhanced permeability and retention (EPR) effect. ${ }^{[1,2]}$

S. S. Pedrosa, C. Gonçalves, Prof. M. Gama

Institute for Biotechnology and Bioengineering (IBB), Centre for Biological Engineering, Campus de Gualtar University of Minho, Braga, Portugal

E-mail: fmgama@deb.uminho.pt

Prof. L. David

Laboratoire Ing'enierie des Mat'eriaux Polym'eres (IMP@Lyon1) CNRS UMR 5223, Universit'e de Lyon, Universit'e Claude Bernard Lyon 1, 15 boulevard Latarjet 69622, Villeurbanne Cedex, France
Hyaluronic acid (HyA) is a natural polysaccharide composed of disaccharide units of D-glucuronic acid and $N$-acetyl-D-glucosamine with $\beta(1,4)$ and $\beta(1,3)$ glucosidic bonds, ubiquitous on the human body. ${ }^{[3,4]}$ It is a highly hydrophilic polysaccharide with great potential as a drug carrier due to its physicochemical and biological properties, such as biocompatibility, biodegradability and non-immunogenicity. ${ }^{[1]}$ Also, HyA allows several chemical modifications including ones that can originate amphiphilic materials capable of self-assembling into nanostructures. Moreover, hyaladherins-a group of high affinity HyA proteins-that include the receptor for hyaluronan-mediated motility (RHAMM) and the HyA receptor $\mathrm{CD} 44$, among others, are important mediators of cancer development and detection. HyA exhibits specific affinity for various cancer cells that overexpress HyA receptors and therefore have great potential for tumour targeting. ${ }^{[1,5,6]}$ 
Various cross-linking approaches have been adopted to improve nanogel features. The cross-linking of nanocarriers could take place on the hydrophilic shell, ${ }^{[7]}$ within the hydrophobic core ${ }^{[8,9]}$ or at the core-shell interface. ${ }^{[10]}$ Redox sensitive nanogel usually containing dissulfide bounds have been used to trigger burst release in response to redox environments. Disulfide bonds represent an interesting approach once though they are stable in the extracellular compartments, may be prone to rapid cleavage with intracellular reducing molecules. Tumour tissues unveil highly reducing ambiences compared with normal ones, with high concentrations of glutathione-a redox molecule. ${ }^{[11]}$

In the present work, we developed a new amphiphilic HyA conjugate by grafting a thiolated hydrophobic chain by amide bond formation, yielding hyaluronic acid-11-Amino-1-undecanethiol hydrochloride (HyA-AT). We studied the self-assembly of the HyA-AT in aqueous environment by ${ }^{1} \mathrm{H}$ nuclear magnetic resonance (NMR) and fluorescence spectroscopy with Nile red, as fluorescent probe. The properties of the resulting nanogel were characterized as to-structure, size, shape, zeta potential, stability and the ability to entrap small hydrophobic molecules and by ${ }^{1} \mathrm{H}$ NMR, fluorescence, cryo-field emission scanning electron microscopy (cryoFESEM), dynamic light scattering (DLS) and SAX analysis. Further, the engineered nanogel was crosslinked by dissulfide bond with a homofunctional crosslinker-1,4Bis(3-[2-pyridyldithio]propionamido)butane (DPDPB) and its - size, structure, stability and ability to entrap hydrophobic drugs was also studied.

\section{Materials}

All reagents were of analytical grade. Sodium hyaluronate $(\mathrm{MW}=7.46 \mathrm{kDa})$ was purchased from Lifecore Biomedical (USA). AG 50W-X8 resin was purchased from Bio-Rad (USA). Absolute ethanol was purchased from Apllichem (Germany). Dimethyl sulfoxide (DMSO), tetrabutylammonium fluoride hydrate (TBA-F), 11-amino-1-undecanethiol hydrochloride (AT), N-hydroxysulfosuccinimide (NHS), 1ethyl-3-[3-dimethylaminopropyl]carbodiimide hydrochloride (EDC), 1,4-Bis(3-[2-pyridyldithio]propionamido)butane (DPDPB) were purchased from Sigma-Aldrich (Italy). The water used for nanogel synthesis and characterization was distillated and ultrapurified (Milli-O).

\section{Methods}

\subsection{Synthesis of Amphiphilic Hyaluronic Acid Conjugate}

Sodium hyaluronate was chemically grafted with a long thiolated alkyl chain by amide bond formation to produce an amphiphilic conjugate, as presented in Scheme 1. ${ }^{[2,12-14]}$

To render sodium hyaluronate soluble in DMSO, the sodium ions of HyA were exchanged with the lipophilic tetrabutylammonium (TBA) ion as described by Oudshoorn et al.. ${ }^{[15]}$ Ion exchange was performed using AG 50W-X8 cation exchange resin. AG 50W (1 g) resin was incubated with an excess of TBA-F (3.5 g) in ultrapure water for $1 \mathrm{~h}$ at

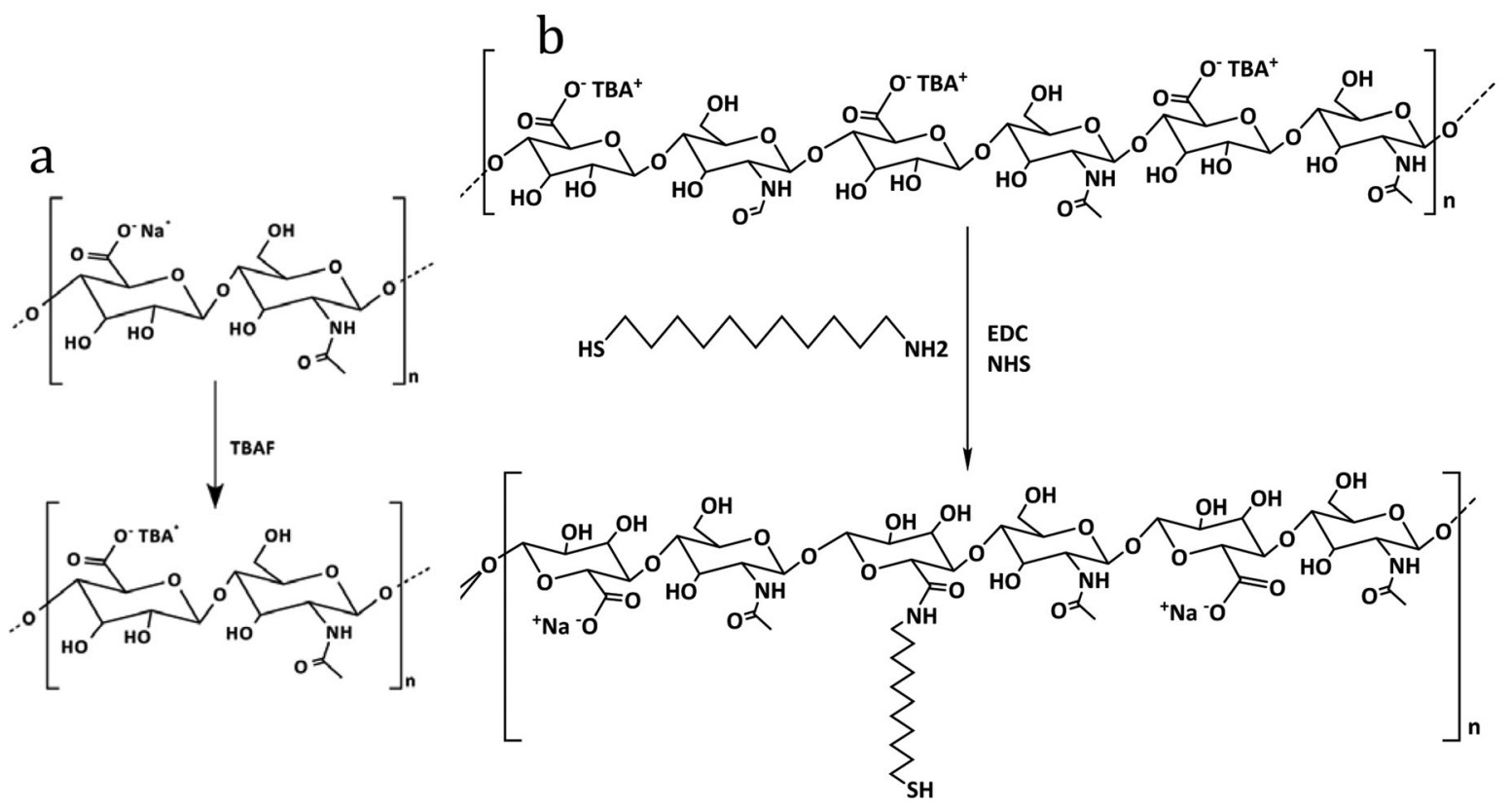

Scheme 1. Representative illustrations of HyA-AT conjugate synthesis, a) ion exchange of sodium hyaluronate and b) amide bond formation reaction.

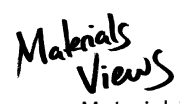

www.MaterialsViews.com 
room temperature and mild agitation. The resin was elutriated, washed and transferred into a $1 \%(\mathrm{w} / \mathrm{v})$ HyA solution in ultrapure water. The exchange of the TBA ions on the resin and the sodium ions of HyA was performed at room temperature with agitation, for $2 \mathrm{~h}$. The removal of the resin was achieved by centrifugation for $2 \mathrm{~min}$ at $5000 \mathrm{rpm}$ (SIGMA 113 centrifuge). The resulting HyA-TBA solution was lyophilized and the fluffy white material was stored at room temperature. ${ }^{1} \mathrm{H}$ NMR spectroscopy was performed to confirm the $\mathrm{Na}^{+}$ions exchange with TBA-F.

Hydrophobic 11-amino-1-undecanethiol hydrochloride (AT) was chemically conjugated to the backbone of modified HyA-TBA in the presence of EDC and NHS. HyATBA (260 mg) was dissolved in anhydrous DMSO at 1\% (w/v) and EDC $(100 \mathrm{mg})$ and NHS $(50 \mathrm{mg})$ were added. Finally, AT (15 mg), also dissolved in anhydrous DMSO was added to the reaction mixture, which was stirred for $24 \mathrm{~h}$ at room temperature. The resulting solution was dialyzed (MWCO $=1000 \mathrm{Da}$ ) first against a $\mathrm{NaCl} 150 \mathrm{mM}$ solution for $3 \mathrm{~d}$-to exchange again the TBA ions for sodium ions-and then distilled water for $2 \mathrm{~d}$. Finally, the solution was freeze-dried and a white cottony material was obtained, corresponding to the HyA-AT conjugate. The degree of substitution of AT molecules in the HyA chain was determined by ${ }^{1} \mathrm{H}$ NMR spectroscopy.

The ${ }^{1} \mathrm{H}$ NMR spectra were obtained using a Varian Unity Plus 300 spectrometer operating at $299.94 \mathrm{MHz}$ and $25^{\circ} \mathrm{C}$.The samples were prepared at $10.0 \mathrm{mg} \mathrm{mL}^{-1}$ in $\mathrm{D}_{2} \mathrm{O}$.

\subsection{Nanogel Assembly Characterization}

\subsubsection{Preparation of Nanogel Dispersion}

The samples were dispersed in distilled water at $1.0 \mathrm{mg} \mathrm{mL}^{-1}$ and filtered through a membrane of $0.22 \mu \mathrm{m}$ pore size and stored at $4{ }^{\circ} \mathrm{C}$ for up to 6 months.

\subsubsection{Dynamic Light Scattering (DLS) Characterization}

The obtained nanogel was characterized as to its size distribution (diameter) and zeta potential by DLS analysis (Zetasizer Nano ZS, Malvern Instruments) at $25^{\circ} \mathrm{C}$. Nanogel dispersion $(1.0 \mathrm{~mL})$ was analysed in a polystyrene cell or in a folded capillary cell, for size and volume distribution or zeta potential measurements, respectively, using a $\mathrm{He}-\mathrm{Ne}$ gas laser (wavelength of $633 \mathrm{~nm}$ ) and a detector angle of $173^{\circ}$. The results presented represent the mean values of polydispersity index (PdI), hydrodynamic diameter and zeta potential of the particles, obtained after five repeated measurements. The Zeta potential values were calculated using Henry's equation.
3.2.3. Cryo-Field-Emission Scanning Electron Microscopy (Cryo-FESEM)

HyA-AT nanogel, $1.0 \mathrm{mg} \mathrm{mL}^{-1}$ concentration was dispersed at in distilled water and frozen in liquid nitrogen at $-200^{\circ} \mathrm{C}$. The sample was transferred to the cryo stage (Gatan, Alto 2500, UK) of an electron microscope (SEM/EDS: FESEM JEOL JSM6301F/Oxford Inca Energy 350). Sample was then fractured and sublimated for 10 minutes at $-95^{\circ} \mathrm{C}$ to remove the superficial ice layer and allow the nanogel to be exposed. Finally, the sample was sputter-coated with gold and palladium at $-140^{\circ} \mathrm{C}$ using an accelerating voltage of $10 \mathrm{kV}$. The observation was performed at $-140^{\circ} \mathrm{C}$ and $15 \mathrm{kV}$.

\subsubsection{Fluorescence Spectroscopy}

The critical aggregation concentration (cac) of HyA-AT nanogel was determined fluorometrically resorting to a hydrophobic probe - Nile Red (NR). Nile red is a hydrophobic fluorescent probe whose fluorescence intensity shifts according to the polarity of the environment. The lyophilized nanogel was dispersed in water in a range of concentrations between 50 and $1.0 \mathrm{mg} \mathrm{mL}^{-1}$ (final volume of $1 \mathrm{ml}$ ), by consecutive dilutions. A stock solution of $4.0 \times 10^{-5} \mathrm{M}$ solution of NR in ethanol was prepared, and $5 \mu \mathrm{L}$ this solution was added to each sample, resulting in a final concentration of NR of $2.0 \times 10^{-7} \mathrm{M}$ and an ethanol content of $0.5 \%$. The samples were agitated overnight at room temperature for homogenisation. Samples fluorescence spectrum were analysed in a Spex Fluorolog 3 spectrofluorimeter at room temperature. The cac was determined by the maximum emission shift of NR and the change of the fluorescence intensity as a function of HyA-AT nanogel concentration.

\subsubsection{SAXS Experiment}

SAXS experiment was carried at the European Synchrotron Radiation Facility (Grenoble, France) on the BM2D2AM beamline. Nanogel samples were set in silica tubes (external diameter $3 \mathrm{~mm}$, wall thickness $0.2 \mathrm{~mm}$, $76 \mathrm{~mm}$ long, from Deutero $\mathrm{GmbH}$ ) with elastomer closure caps to avoid water evaporation (Deutero $\mathrm{GmbH}$ ). The incidence photon energy was $16000 \mathrm{keV}$ and a 2D CCD X-ray detector (Ropper Scientific) was used. The images were corrected for camera distortion, dark image reading and flat field response of the detector. Finally, the image center ("gravity center" of the incident beam) was determined with attenuators and radial averages yielded 1D profiles (processing carried on the beamline, with bm2img software). Silver behenate powder was used as standard for calibration. The scattering contribution was eliminated by subtracting the attenuation coefficient of water filled glass tube. 
HyA-AT nanogel was prepared as described earlier at 10.0 and $30.0 \mathrm{mg} \mathrm{mL}^{-1}$ concentration.

\subsection{DPDPB Mediated Crosslinking}

\subsubsection{Crosslinked Nanogel Synthesis}

1,4-Bis(3-[2-pyridyldithio]propionamido)butane (DPDPB), is a homobifunctional crosslinking agent that contains dithiopyridyl groups on both ends of the molecule that react with free sulfhydryl groups.

Lyophilized HyA-AT was dispersed in water at a concentration of $1.0 \mathrm{mg} \mathrm{mL}^{-1}$ as described earlier. As reported by Wittrup, 2012, ${ }^{[17]}$ a $10 \mathrm{mg} \mathrm{mL}^{-1}$ stock solution of DPDPB in DMSO was prepared and added to the nanogel dispersion at a molar ratio of 2:1 free sulfhydryl groups of HyA-AT conjugate. The amount of DMSO in the reaction was inferior to $1 \%(\mathrm{v} / \mathrm{v})$. Air was injected through a syringe in the reaction mixture for $15 \mathrm{~min}$. Then, the suspension was gently stirred overnight at $30^{\circ} \mathrm{C}$.

The reaction was then dialyzed against water in an $M W C O=1 \mathrm{kDa}$ membrane bag. The resulting solution was freeze-dried and lyophilized.

The crosslinked HyA-AT-DPDPB nanogel was analysed by ${ }^{1} \mathrm{H}$ NMR spectroscopy using a Varian Unity Plus 300 spectrometer operating at $299.94 \mathrm{MHz}$ and $25^{\circ} \mathrm{C}$.

\subsubsection{Crosslinked Nanogel Characterization}

\subsubsection{UV-Vis Spectroscopy}

The successful disulfide linkage between DPDPB and free sulfhydryl groups of HyA-AT nanogel causes a shift of the DPDPB absorbance peaks of $237 \mathrm{~nm}\left(\varepsilon=1.2 \times 10^{4} \mathrm{M}^{-1} \mathrm{~cm}^{-1}\right)$ to $272 \mathrm{~nm}$ and the peak at $287 \mathrm{~nm}\left(\varepsilon=8.8 \times 10^{3} \mathrm{M}^{-1} \mathrm{~cm}^{-1}\right)$ is shifted to $343 \mathrm{~nm}\left(\varepsilon=8.08 \pm 0.3 \times 103 \mathrm{M}^{-1} \mathrm{~cm}^{-1}\right) \cdot{ }^{[18]}$ Therefore, UV-Vis absorption spectra of a $200 \mu \mathrm{L}$ sample of the HyA-AT-DPDPB reaction mixture was recorded on a JASCO V560 equipment. A control with unreacted DPDPB molecule dispersed in DMSO at a concentration of $0.2 \mathrm{mg} \mathrm{mL}^{-1}$ was also analysed. The dialysed suspension was again analysed by UV-Vis spectroscopy to ascertain the elimination of the two pyridine-2-thione a product of the DPDPB conjugation with AT and responsible for the $343 \mathrm{~nm}$ peak.

\subsubsection{Cryo-Field-Emission Scanning Electron Microscopy (CrYO-FESEM)}

HyA-AT-DPDPB nanogel was dispersed at a concentration of $1.0 \mathrm{mg} \mathrm{mL}^{-1}$ in distilled water and frozen in liquid nitrogen at $-200{ }^{\circ} \mathrm{C}$. The sample were analysed in an electron microscope (SEM/EDS: FESEM JEOL JSM6301F/ Oxford Inca Energy 350) as described earlier.

\subsubsection{Dynamic Light Scattering (DLS) Characterization}

The lyophilized crosslinked nanogel (HyA-AT-DPDPB) were dispersed in distilled water at $1.0 \mathrm{mg} \mathrm{mL}^{-1}$ and filtered through a $0.22 \mu \mathrm{m}$ membrane pore and diluted sequentially to a concentration of $1.0 \mu \mathrm{g} \mathrm{mL}^{-1}$. The solutions were then characterized as to its hydrodynamic size diameter by DLS analysis (Zetasizer Nano ZS, Malvern Instruments) at $25^{\circ}$. The values presented represent the mean values of PdI and size diameter of particles after five repeated measurements.

\subsubsection{Redox Sensitive Crosslinked Nanogel Characterization}

To assess the susceptibility of crosslinked nanogel to reducing environment that disrupt dissulfide bonds, more diluted sample of HyA-AT-DPDPB nanogel-1.0 $\mu \mathrm{g} \mathrm{mL}^{-1}-$ was further treated with dithiothreitol (DTT), a potent reducing agent. DTT was used to reduce the dissulfide bonds between DPDPB molecules and AT residues of the HyA-ATDPDPB nanogel. To the HyA-AT-DPDPB solution with $1.0 \mu \mathrm{g} \mathrm{mL}^{-1}$ in distilled water, a DTT stock solution in DMSO was added, to a final concentration of $1.0 \mathrm{~mm}$. The final solution was stirred and incubated for $30 \mathrm{~min}$. The sample was characterized as to its hydrodynamic diameter by DLS analysis soon after preparation and two weeks after, to assess its stability under redox conditions. The values presented represent the mean values of PdI and diameter of particles after five repeated measurements.

\subsection{Drug Loading Efficiency}

Curcumin (CM) is a hydrophobic drug insoluble in aqueous solvents but soluble in organic ones. Simvastatin (SV) is also a hydrophobic drug poorly soluble in water $\left(>\mathrm{mg} \mathrm{L}^{-1}\right)$ and soluble in organic solvents (PubChem Substance and Compound database, substance identifier number SID:54454) ${ }^{[19]}$ Curcumin was solubilized in ethanol at a concentration of $1.0 \mathrm{mg} \mathrm{mL}^{-1}$ as a stock solution. A volume of $10 \mu \mathrm{L}$ of the curcumin stock solution was incubated with $1.0 \mathrm{mg} \mathrm{mL}^{-1}$ nanogel dispersions of HyA-AT and HyA-ATDPDPB, prepared as described earlier. The final curcumin concentration attained in the samples was $30 \mathrm{~mm}$ and the ethanol content was $1 \%(\mathrm{v} / \mathrm{v})$. In a similar way, a $5.0 \mathrm{mg}$ $\mathrm{mL}^{-1}$ stock solution of ethanol solubilized SV was prepared and $6.0 \mu \mathrm{L}$ were added to analogous nanogel samples. The final SV concentration in the samples was $71.7 \mu \mathrm{M}$ and the ethanol content was less than $1 \%(\mathrm{v} / \mathrm{v})$. Also, a negative control and a positive control of drug loading were performed in the same volume and with the same final concentration, in water and ethanol, respectively. The samples were incubated overnight at room temperature in a turning wheel. Finally, all the samples were centrifuged at

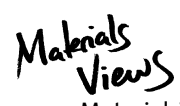

www.MaterialsViews.com 
$13000 \mathrm{rpm}$ (SIGMA 113 centrifuge) for $10 \mathrm{~min}$ to remove the insoluble drugs. The samples supernatant were analysed in a JASCO V560 system and the UV-Vis absorption spectra was recorded. Soluble CM has a yellow tone colour and a maximum absorbance at $428 \mathrm{~nm}$. Soluble SV is a colourless solution with maximum absorbance at 238 and $247 \mathrm{~nm}$.

\section{Results}

\subsection{Synthesis of Amphiphilic Hyaluronic Acid Conjugate}

Amphiphilic hyaluronic acid conjugate was synthetized as shown in Scheme 1a. Sodium hyaluronate was first converted to its tetrabutylammonium salt to enhance the solubility in polar aprotic organic solvents. The exchange with the lipophilic cation was confirmed by ${ }^{1} \mathrm{H}$ NMR in $\mathrm{D}_{2} \mathrm{O}$ by the peaks at $\delta=0.97\left(\mathrm{~m}, 12 \mathrm{H}, \mathrm{N}^{+}-\left[\left(\mathrm{CH}_{2}\right)_{3}-\mathrm{CH}_{3}\right]_{4}\right)$; $\delta=1.40\left(\mathrm{~m}, 8 \mathrm{H}, \mathrm{N}^{+}-\left[\left(\mathrm{CH}_{2}-\mathrm{CH}_{2}-\mathrm{CH}_{2}-\mathrm{CH}_{3}\right]_{4}\right) ; \delta=1.64(\mathrm{~m}\right.$, $8 \mathrm{H}, \mathrm{N}^{+}-\left[\left(\mathrm{CH}_{2}-\mathrm{CH}_{2}-\mathrm{CH}_{2}-\mathrm{CH}_{3}\right]_{4}\right)$ and $\delta=3.82(\mathrm{~m}, 8 \mathrm{H}$, $\mathrm{N}^{+}-\left[\left(\mathbf{C H}_{\mathbf{2}}-\mathrm{CH}_{2}-\mathrm{CH}_{2}-\mathrm{CH}_{3}\right]_{4}\right){ }^{[20]}$ The degree of substitution (DS) of the sodium ion by the tetrabutylammonium ion, defined, as the number of TBA molecules per 100 residues of HyA, was calculated based on the ${ }^{1} \mathrm{H} N M R$ in $\mathrm{D}_{2} \mathrm{O}$ of HyA-TBA. The DS obtained for different batches was reproducible and approximately $100 \%$.

Further conjugation of hyaluronate TBA salt with 11Amino-1-undecanethiol (AT) by amide bond formation was performed as shown in Scheme $1 \mathrm{~b}$. The amino group of AT reacted with the carboxylic groups of hyaluronic acid in the presence of 1-ethyl-3(3-dimethylaminopropyl)carbodiimide (EDC) and $N$-hydroxysuccinimide (NHS) through carbodiimide chemistry. The grafting of the hydrophobic chain and the respective DS, defined as the number of AT molecules per 100 disaccharide units of HyA, were confirmed by ${ }^{1} \mathrm{H}$ NMR spectroscopy, as shown in Figure 1. The assignments and chemical shifts of the ${ }^{1} \mathrm{H}$ signals in $\mathrm{D}_{2} \mathrm{O}$ used in the determination of the DS are indicated in Figure 1. The peaks correspondent to hyaluronic acid used to the calculus are assigned to 11 protons - and are identified in Figure 1, with the number 2-which are: $\delta=4.51$ (G1), $\delta=4.61(\mathrm{~N} 1), \delta=3.92(\mathrm{~N} 2), \delta=3.63$ (G3), $\delta=3.74-3.85$ (N3, N6, G4, G5) and $\delta=3.51-3.62$ (N4, N5). ${ }^{[21]}$ The peaks assigned to AT protons used in the determination of the DS are $\delta=1.2-1.4\left(14 \mathrm{H}^{+}, \mathrm{N}^{+}-\left(\mathrm{CH}_{2}\right)_{2}-\left(\mathbf{C H}_{2}\right)_{7}-\left(\mathrm{CH}_{2}\right)_{2}-\mathrm{SH}\right)$.

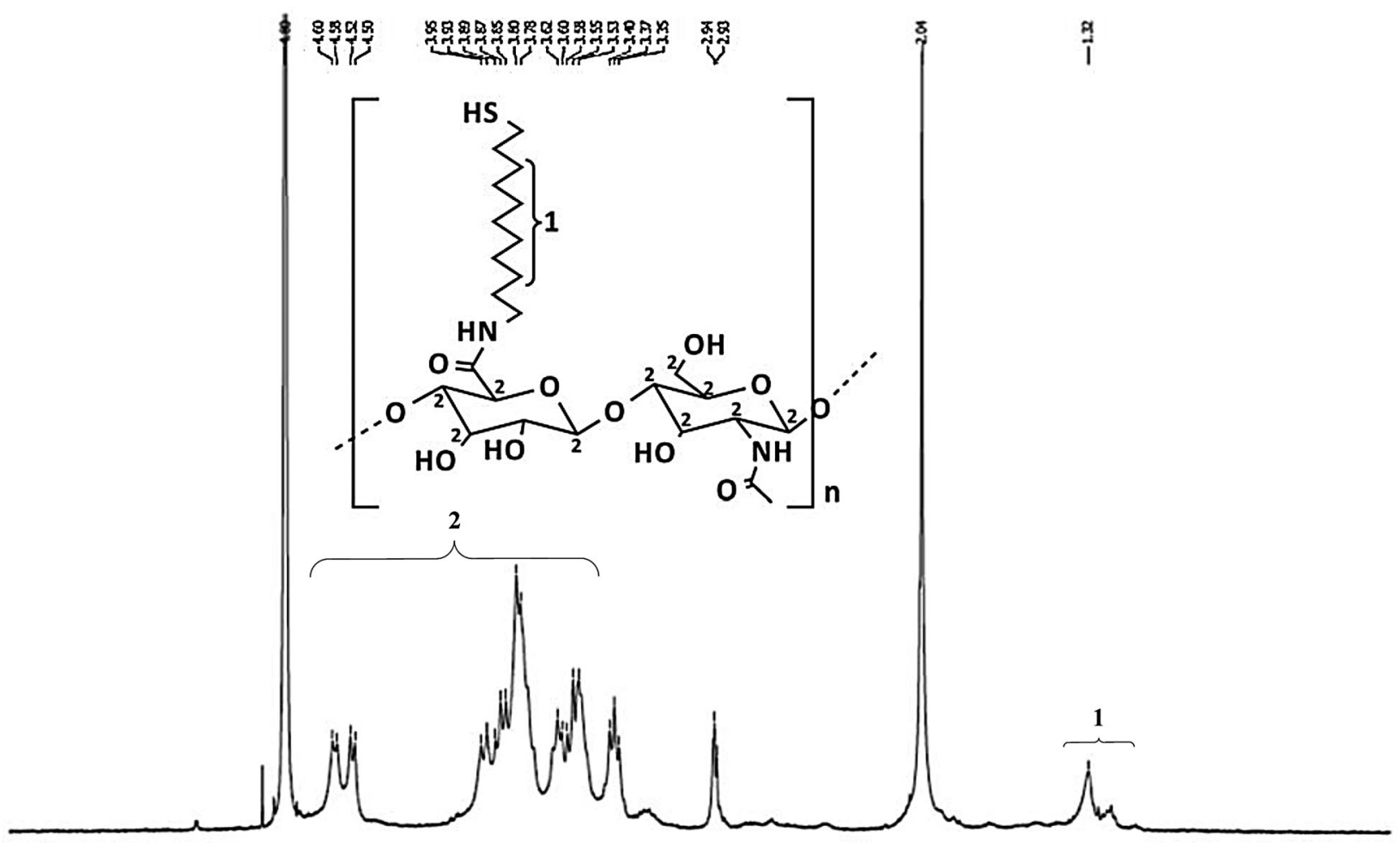

\begin{tabular}{|c|c|c|c|c|c|c|c|c|c|c|}
\hline 5.5 & 5.0 & 4.5 & 4.0 & 3.5 & $\stackrel{3.0}{1}$ & 2.5 & 20 & 1.5 & 1.0 & 0.5 \\
\hline
\end{tabular}

Figure 1. ${ }^{1} \mathrm{H}$ NMR spectrum of HyA-AT nanogel in $\mathrm{D}_{2} \mathrm{O}$ at $25^{\circ} \mathrm{C}$ and a schematic representation of the HyA-AT conjugate. 
The AT DS was calculated according to the following equation:

$$
D S_{A T}=\frac{14 \times(\delta 1.2 \rightarrow 1.4)}{11 \times(\delta 3.51 \rightarrow 4.61} \times 100
$$

The DS was about $11 \%$, meaning that 1 out of every 11 disaccharide units are chemically modified with AT. The yield of the reaction was about $67 \%$ and was reproducible in all batches.

\subsection{Nanogel Characterization}

\subsubsection{Dynamic Light Scattering (DLS) Characterization}

The grafting of AT molecules to hydrophilic backbone of HyA results in an amphiphilic molecule capable of selfassembling into nanostructures in aqueous environment. HyA-AT nanogel was fully characterized by DLS analysis regarding its size distribution by intensity (Figure 2a) or volume (Figure $2 \mathrm{~b}$ ) and zeta potential (Figure 2c). Size distribution is an intensity profile in which the light scattered by the particles is conditioned by its size. The first order result from a DLS experiment is the intensity distribution of particle sizes. The intensity distribution is weighted according to the scattering intensity of each particle fraction. As such, the intensity distribution can be somewhat misleading, in that a small amount of aggregates or larger particles can dominate the distribution.

The intensity distribution (quite sensitive to the presence of larger particles) can be converted, using Mie theory, to a volume distribution. The conversion to volume distribution highlights smaller populations of nanoparticles, leading to, in our opinion, more realistic size distribution.

When dispersed in water at $1.0 \mathrm{mg} \mathrm{mL}^{-1}$ concentration, the nanogel reveals a bimodal size distribution with a smaller population around $20 \mathrm{~nm}$ and another with about $150 \mathrm{~nm}$, corresponding to a mean size diameter of $80.2 \pm 0.4 \mathrm{~nm}(n=5)$. The self-assembly of the engineered nanogel was tested in the presence of a reducing agentDTT-and the resulting mean size diameter was $91.85 \pm 0.410 \mathrm{~nm}$. This proves, that in this case the thiol groups of the hydrophobic chains present in the HyA-AT nanogel do not seem to react with one another, in a spontaneous manner.

Nanocarriers smaller than $200 \mathrm{~nm}$ can avoid uptake by the mononuclear phagocyte system, the longer circulation time allowing specific interaction with the target tissues. $^{[22]}$ Analysing the volume distribution profile (Figure $2 \mathrm{~b}$ ) the smallest population at $20 \mathrm{~nm}$ represents approximately $95 \%$ being the main population.

The polydispersity index of the nanogel size distribution was about 0.4. The zeta potential obtained for HyA-AT nanogel was $-19.3 \pm 1.97 \mathrm{mV}(n=5)$ in average. Negatively charged particles have demonstrated enhanced circulation time within the body also due to non-specific binding to serum proteins and allowed high storage stability owing to electrostatic repulsion between the particles. ${ }^{[4,6]}$ Also, the negative charge of the particles confirms the presence of HyA at the surface of the nanogel as it was expected and is due to the ionized carboxylate groups.

The morphology of the HyA-AT nanogel was examined by Cryofield emission scanning electron microscope (Cryo-
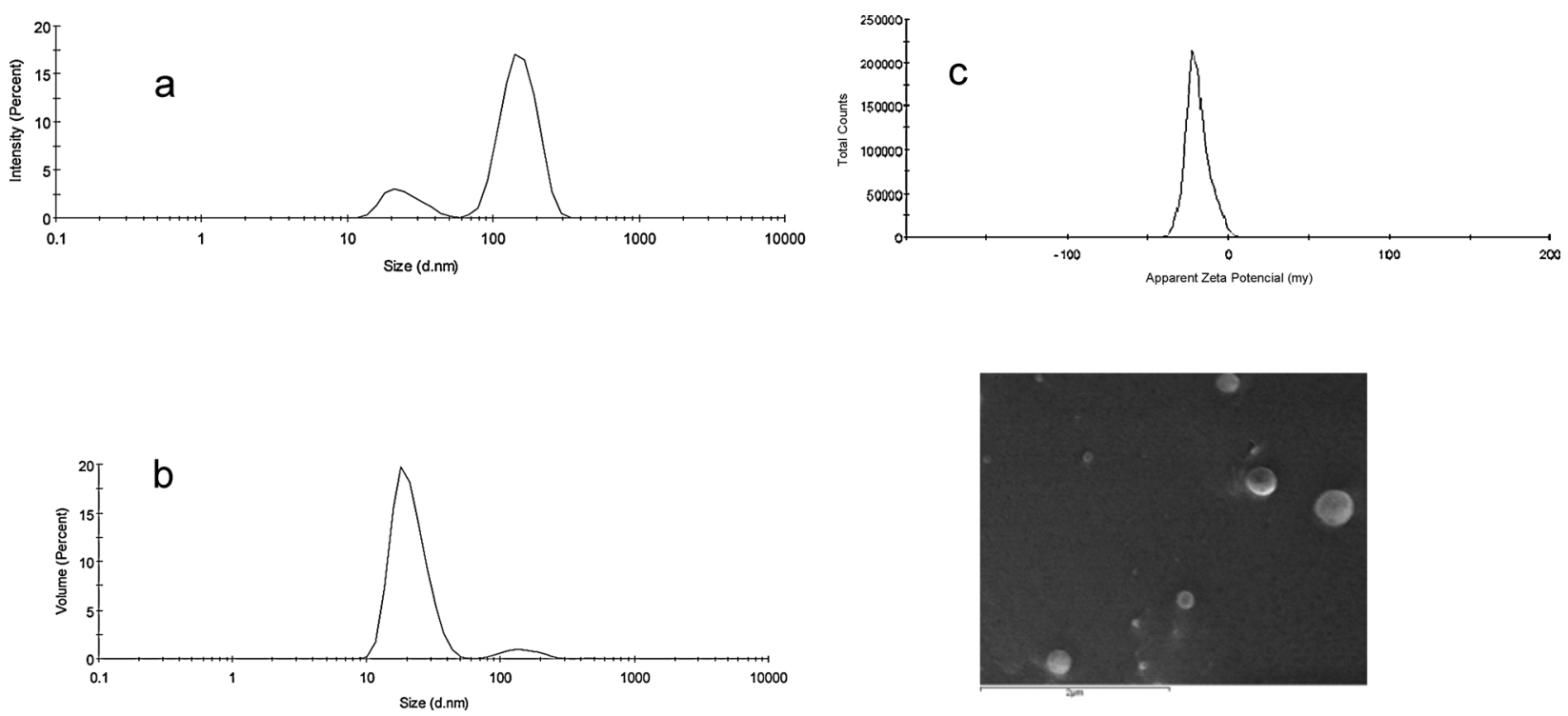

Figure 2. a) Size distribution by intensity and b) by volume and, c) zeta potencial of the HyA-AT nanogel. d) Cryo-FESEM image of HyA-AT nanogel (scale bar $=2 \mu \mathrm{m})$.

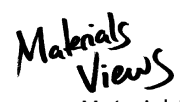

www.MaterialsViews.com 
FESEM) and is shown in Figure $2 \mathrm{~d}$. The nanogel particles were well dispersed with spherical shape. Size and volume distribution profiles from DLS analysis were confirmed in the Cryo-FESEM images, where particles with size corresponding to the two populations identified by DLS are indeed visible.

\subsubsection{Stability of HyA-AT Nanogel}

The stability of HyA-AT nanogel was evaluated at different $\mathrm{pH}$ and at $25^{\circ} \mathrm{C}$ and also following incubation for $7 \mathrm{~d}$ at $4{ }^{\circ} \mathrm{C}$. In pH4 phosphate-citrate buffer, the mean size was $112.4 \pm \cdot 10.21 \mathrm{~m}\left(121.8 \pm 9.2 \mathrm{~nm}\right.$ after $7 \mathrm{~d}$ at $\left.4{ }^{\circ} \mathrm{C}\right)$ and in $\mathrm{pH} 7.4$ phosphate buffer saline, the mean size was $90.1 \pm 0.419 \mathrm{~nm}\left(88.9 \pm 0.4 \mathrm{~nm}\right.$ after $7 \mathrm{~d}$ at $\left.4{ }^{\circ} \mathrm{C}\right)$. The nanogel dispersed in distilled water at $1.0 \mathrm{mg} \mathrm{mL}^{-1}$ was stored up to 6 months at $4{ }^{\circ} \mathrm{C}$ and demonstrated high stability in terms of size distribution as may be seen in Figure 3.

\subsubsection{Determination of Critical Aggregation Concentration of the Nanogel}

Critical aggregation concentration (cac) of the HyA-AT conjugates was determined by fluorescence spectroscopy using Nile Red (NR) as a fluorescent probe. Nile red is a hydrophobic molecule, whose maximum fluorescent emission wavelength is dependent of the polarity of the surrounding environment. When transferred from nonpolar to hydrophobic environments, NR emission spectrum is shifted to higher wavelengths and this feature turns it suitable to assess the cac of amphiphilic polymers. ${ }^{[23,24]}$

For the determination of the cac of HyA-AT conjugate, NR was added to a series of conjugate dispersions with concentration comprised between $10.0 \mu \mathrm{g} \mathrm{L}^{-1}$ and $1.0 \mathrm{~g} \mathrm{~L}^{-1}$. The fluorescence emission spectra of NR at different concentrations of HyA-AT nanogel are represented in

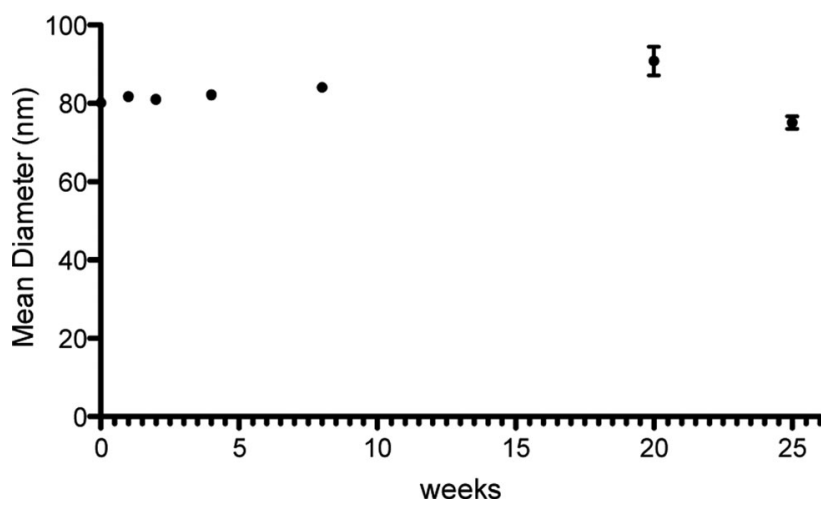

Figure 3. Colloidal stability of HyA-AT nanogel evaluated by average particle size (diameter-nm) of the nanogel as a function of time.

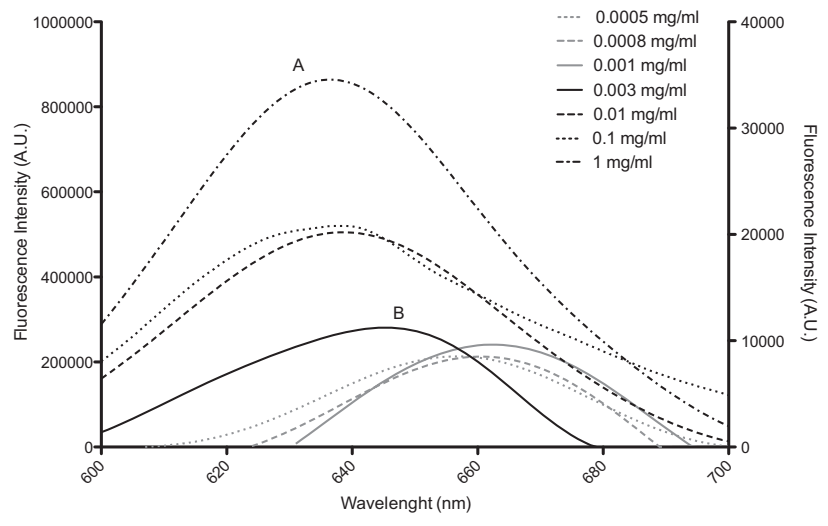

Figure 4. Emission spectra of Nile Red in a concentration of $2.0 \times 10^{-7} \mathrm{M}$ as a function of HyA-AT nanogel concentration.

Figure 4 and the plotted maximum fluorescence emission (solid line) and fluorescence intensity (doted line) in Figure 5. From these results we may conclude that at concentrations below cac, amphiphilic HyA-AT molecules do not bear any specific organization (premicellar concentration, zone A, Figure 4). Near cac, the maximum fluorescence emission wavelength of NR decreased abruptly from about 660 to $610 \mathrm{~nm}$ (zone B, Figure 4 and 5) and the fluorescence increases (Figure 5, doted line). These changes indicate that the immediate environment of the fluorescent probe changed from polar to less polar due to the interactions between NR and the AT pendant groups of HyA-AT, organized through self-assembling at the higher concentrations, forming hydrophobic nanodomains. Hence, the concentration at which the amphiphilic HyAAT conjugate self-assembles onto nanostructures with hydrophobic nanodomains is establish between 0.8 and $1.0 \mathrm{mgL}^{-1}$. The cac reported for similar amphiphilic materials was $0.042 \mathrm{mg} \mathrm{mL}^{-1}$ for HyA-ceramide conjugate, ${ }^{[22]} 67.5 \mathrm{mg} \mathrm{L}^{-1}$ for HyA- g-all-trans retinoid acid ${ }^{[25]}$ and $37.3-10.0 \mu \mathrm{g} \mathrm{mL}^{-1}$ for HyA-C18 conjugate. $^{[13]}$ These low cac values indicate that HyA-AT nanogel might have

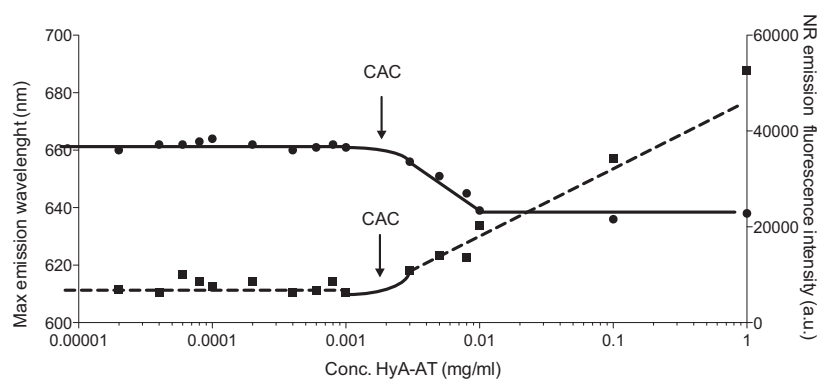

Figure 5. Plot data representation of the fluorescence intensity (0) and maximum emission wavelength ( $\square$ ) of Nile Red as a function of HyA-AT concentration. 


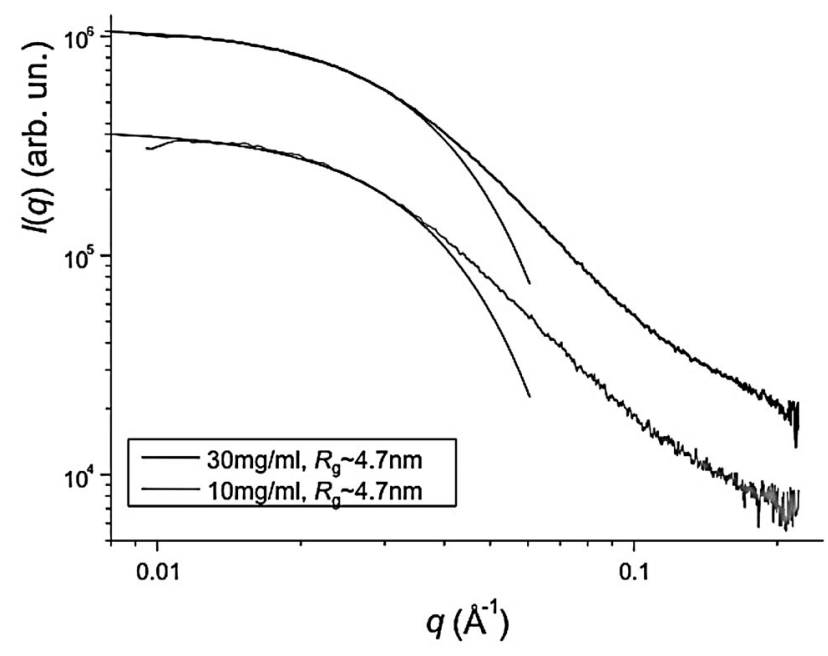

Figure 6. SAXS analysis of HyA-AT nanogel (water dispersion) at 30.0 and $10.0 \mathrm{mg} \mathrm{mL}^{-1}$ concentrations. good dilution stability in the bloodstreams after intravenous injection. ${ }^{[26]}$

\subsubsection{SAXS Experiments}

The morphology and inner structure of the HyA-AT nanogel was studied by Small Angle.

X-ray Scattering (SAXS). The scattering patterns shown in Figure 6 demonstrate the existence of hydrophobic nanodomains. These scattering nanodomains present a gyration radius between 4.6 and $4.8 \mathrm{~nm}$ and irregular shape, which is an expected feature since they are formed by AT chains. For the nanogel population with lower size $(20 \mathrm{~nm})$, it may be speculated that each particle presents at least one hydrophobic nanodomain, surrounded by a hydrophilic corona. However, as observed in a work on a similar material, ${ }^{[27]}$ each nanogel particle may contain

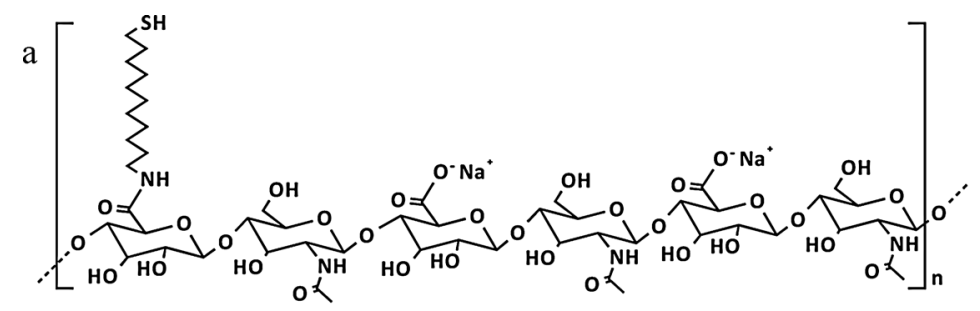
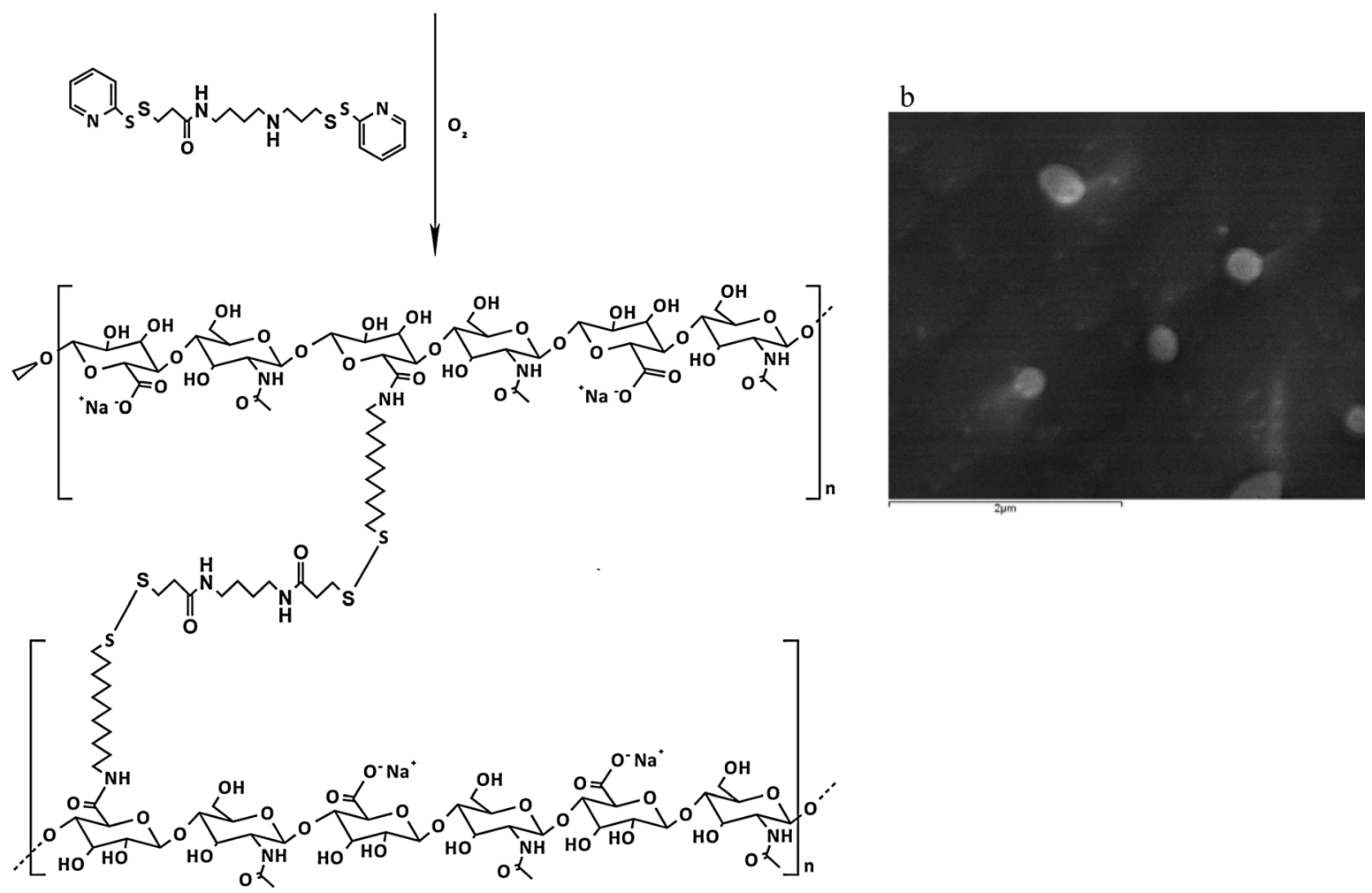

Figure 7. A) Schematic representation of the crosslinking reaction between HyA-AT conjugate and DPDPB through disulfide bond. B) CryoFESEM image of HyA-AT-DPDPB nanogel (scale bar $=2 \mu \mathrm{m})$.

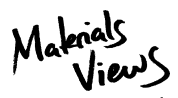

www.MaterialsViews.com 
www.mbs-journal.de

several hydrophobic nanodomains, as it is quite likely the case for the larger particles.

\subsection{DPDPB Mediated Crosslinking}

\subsubsection{Crosslinked Nanogel Synthesis}

We developed an original way of reticulating the hydrophobic polymer chains of HyA-AT nanogel, by redoxsensitive bonds, as represented in Figure 7. The reticulation of the chains of amphiphilic hyaluronic acid conjugates was fulfilled using a homobifunctional sulfhydryl-reactive crosslinker-1,4-Bis(3-[2-pyridyldithio]propionamido)butane (DPDPB). DPDPB reacts with the sulfhydryl groups of $\mathrm{AT}$ residues releasing the two pyridine-2-thione of the terminus of the molecule. Conjugation with DPDPB results in a 14-atom spacer of approximately $16 \AA$ in length (Figure 7).

$\mathrm{A}^{1} \mathrm{H}$ NMR spectrum of the crosslinked and non-crosslinked HyA-AT nanogel was performed to confirm the successful conjugation of DPDPB, which was indeed confirmed by the presence of the peaks at 1.36-1.38, 1.55 and $1.85 \mathrm{ppm}$ assigned to the methyl groups of DPDPB (Figure 8).

\subsubsection{Crosslinked Nanogel Characterization}

\subsubsection{UV-Vis Spectroscopy}

The release of the two pyridine-2-thione during the conjugation reaction causes the shift of the DPDPB absorbance peaks of $237 \mathrm{~nm}\left(\varepsilon=1.2 \times 104 \mathrm{M}^{-1} \mathrm{~cm}^{-1}\right)$ that is shifted to $272 \mathrm{~nm}$ and the peak at $287 \mathrm{~nm}(\varepsilon=8.8 \times$ $\left.103 \mathrm{M}^{-1} \mathrm{~cm}^{-1}\right)$ that is shifted to $343 \mathrm{~nm}(\varepsilon=8.08 \pm 0.3 \times$ $103 \mathrm{M}^{-1} \mathrm{~cm}^{-1}$ ) (Hermanson, 2010). Therefore, the coupling of DPDPB was confirmed by monitoring the absorbance spectrum of DPDPB by UV-Vis spectroscopy (JASCO V560) and the appearance of the $343 \mathrm{~nm}$ peak (Figure 9).

The monitoring of the conjugation by UV spectroscopy was performed prior and after dialysis, once the dialysis was intended to eliminate the released pyridine-2thione and the unreacted DPDPB (Figure 8). The peak at $343 \mathrm{~nm}$ in the reticulated nanogel (before dialysis) demonstrates the conjugation of DPDPB and the release of the pyridine-2-thione (doted line, Figure 8), effectively removed by dialysis together with the unreacted DPDPB molecules, as proven by the withdrawal of the $343 \mathrm{~nm}$ peak and the presence of the $272 \mathrm{~nm}$ peak (grey line, Figure 9).

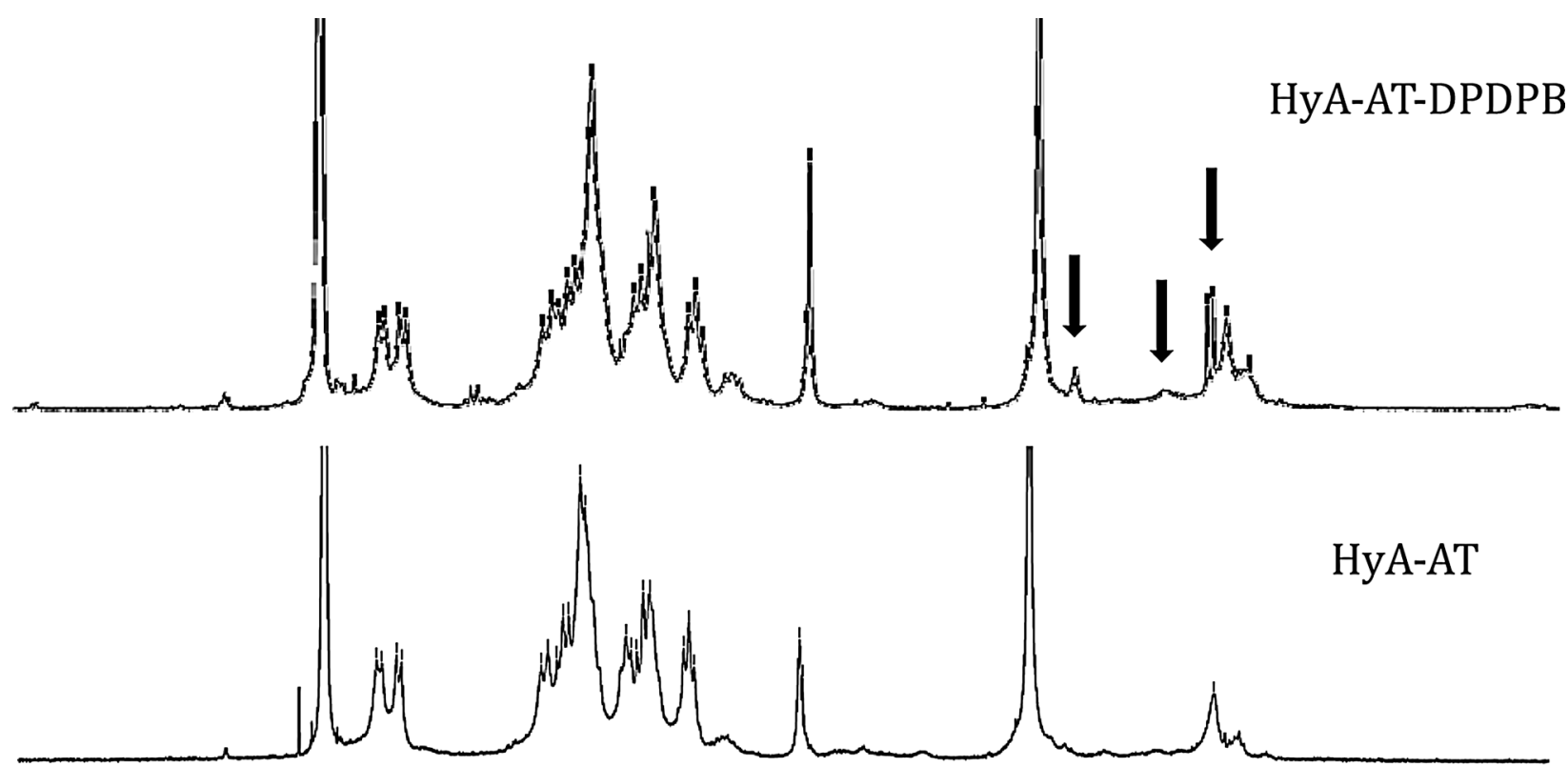

5.5

5.0

4.0

3.5

3.0
$\mathbf{f 1}(\mathrm{nnm})$

2.5

2.0

1.5

1.0

0.5

Figure 8. ' $\mathrm{H}$ NMR spectrum of HyA-AT-DPDPB and HyA-AT nanogels in $\mathrm{D}_{2} \mathrm{O}$ at $25^{\circ} \mathrm{C}$ and the evidence of the presence of DPDPB ascribed peaks. 


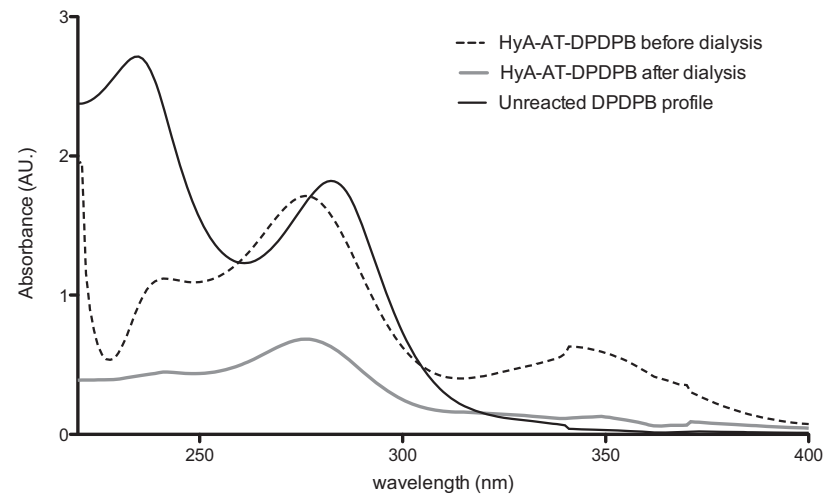

Figure 9. UV-Vis absorbance spectrum of HyA-AT-DPDPB nanogel.

\subsubsection{Cryo-Field-Emission Scanning Electron Microscopy (CrYO-FESEM)}

HyA-AT-DPDPB nanogel was prepared at a concentration of $1 \mathrm{mg} \mathrm{mL}^{-1}$ in distilled water, frozen and analysed in an electron microscope (SEM/EDS: FESEM JEOL JSM6301F/ Oxford Inca Energy 350).

The Cryo-FESEM images show that the reticulated nanogel was also spherical in shape (Figure 7).

\subsubsection{Dynamic Light Scattering (DLS) Characterization}

In Figure 10, we present the volume distribution profiles of reticulated and non-reticulated nanogel, using samples with concentrations between 1.0 and $0.001 \mathrm{mg} \mathrm{mL}^{-1}$ - the later, a concentration below de cac of the HyA-AT nanogel. The non-reticulated nanogel showed stability in terms of mean size values and volume distribution profile when

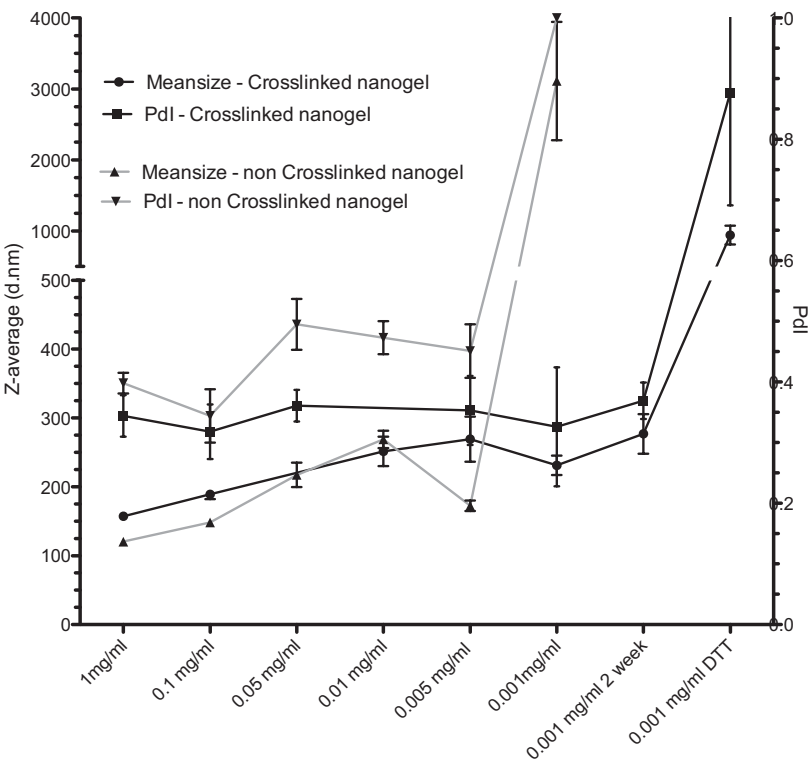

Figure 11. Plot data representation of the mean size diameter of HyA-AT and HyA-AT-DPDPB nanogel particles as function of nanogel concentration and the effect of a reducing agent in the crosslinked nanogel.

diluted to a concentration of $5 \mu \mathrm{g} \mathrm{mL}^{-1}$. Once further diluted, at concentrations below the cac-1.0 $\mu \mathrm{g} \mathrm{mL}^{-1}$-it was possible to detect disassembling of the nanogel as seen in the volume distribution profile and by the mean size value (Figure 11).

The study of the dilution effect on the DPDPBreticulated nanogel was also performed in the same concentration range. The volume distribution profile and the mean size diameter of HyA-AT-DPDPB nanogel were

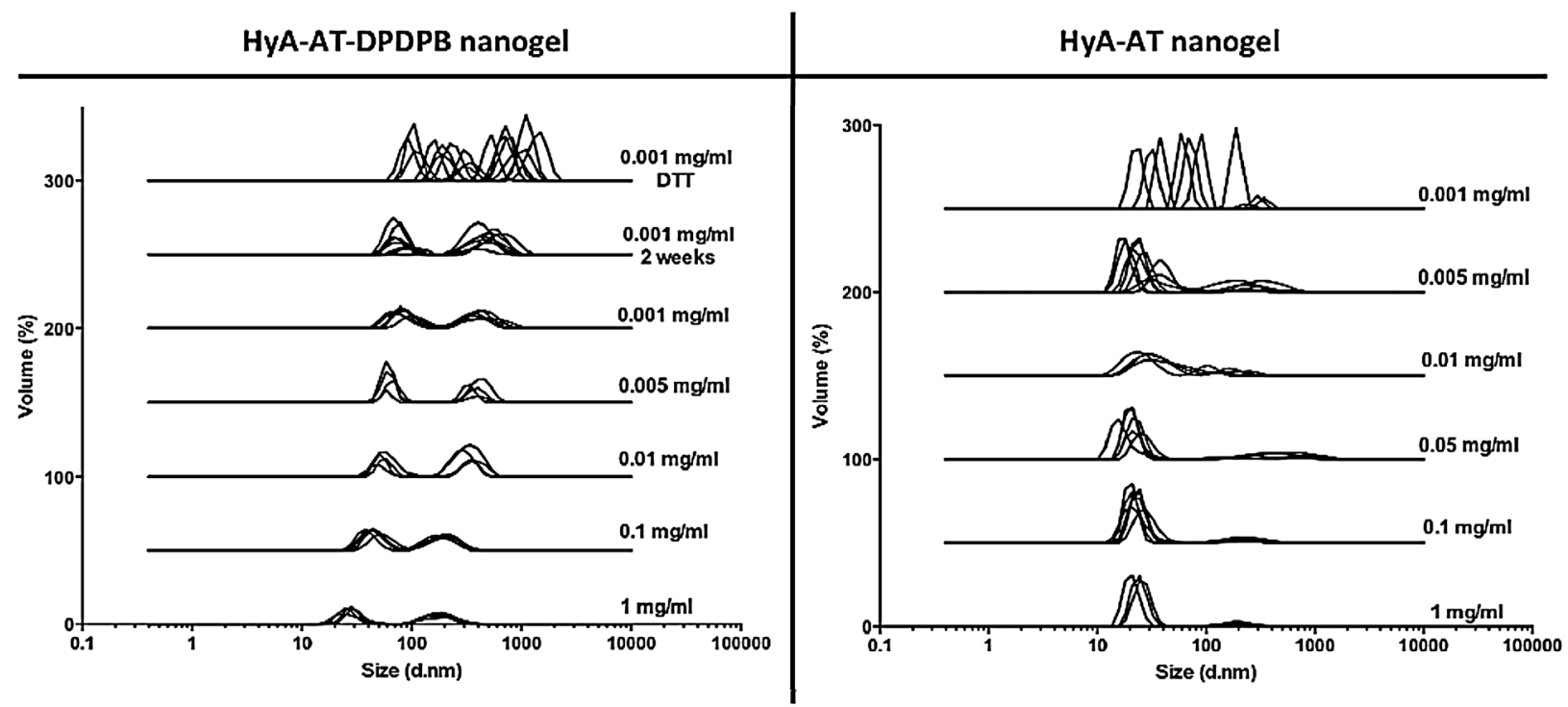

Figure 10. Comparison of hydrodynamic particle volume distribution profile of HyA-AT and HyA-AT-DPDPB nanogels upon dilution, evaluated by DLS analysis.

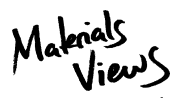

www.MaterialsViews.com 
analysed by DLS (Figure 10, 11). Remarkably, the nanogel volume distribution profile and mean size was maintained even bellow the cac. The lower concentration$1 \mu \mathrm{gL}^{-1}$ - was evaluated after 2 weeks to assess the stability and it was noticeable that the nanogel preserved its supramolecular structure. Similar results were obtained by other researchers. ${ }^{[28,29]}$

Interestingly, the reticulated nanogel volume distribution showed more equitable populations than in the nonreticulated, indicating that the crosslinking caused an increase in the larger population. This may be due to the effect of the DPDPB spacer in the reorganization of the HyA and AT chains that become deviated increasing the larger population, around $150 \mathrm{~nm}$.

Hence, the reticulated nanogel-although with slightly larger particles - presents a narrower distribution, demonstrated by the smaller PdI values obtained by DLS analysis (Figure 11).

\subsubsection{Redox Sensitive Crosslinked Nanogel Characterization}

Nonetheless, the more diluted sample was further treated with dithiothreitol (DTT), a reducing agent to disrupt the reversible DPDPB conjugation. The reducing agent recoiled the reticulating effect of DPDPB by breaking the disulfide bond between the 14-atom spacer with AT residues of HYAAT nanogel.

\subsection{Drug Loading Efficiency}

The drug entrapment efficiency of HyA-AT nanogel was determined using curcumin and simvastatin as model hydrophobic drugs. The encapsulation efficiency (EE) was assessed spectrophotometrically and expressed in concentration of drug incorporated into the nanogel. Simvastatin is a hydrophobic statin ${ }^{[30]}$ used in the treatment of dyslipidaemias and recent findings indicate that also exhibit antiinflammatory properties such as inhibiting the production of pro-inflammatory cytokines, C-reactive protein, cellular adhesion molecules and chemotaxic molecules. ${ }^{[31,32]}$ Curcumin (diferuloylmethane) is a low molecular weight natural polyphenolic compound soluble in ethanol and insoluble in water with antioxidant, anti-inflammatory and anticancer properties. ${ }^{[33]}$ These were used as a model drug for assessing the loading capability of HyA-AT nanogel. Since both drugs prefer hydrophobic environments we tested their loading onto de nanogel hydrophobic domains.

Curcumin (CM) and simvastatin (SV) exhibit strong absorption at $428 \mathrm{~nm}$ and at 238 and $247 \mathrm{~nm}$, respectively, allowing the use of spectrophotometrical analysis to quantify the amount of drug incorporated into the nanogel. An ethanolic solution of curcumin (stock solution) was added to $1.0 \mathrm{mg} \mathrm{mL}^{-1}$ nanogel aqueous suspension-final

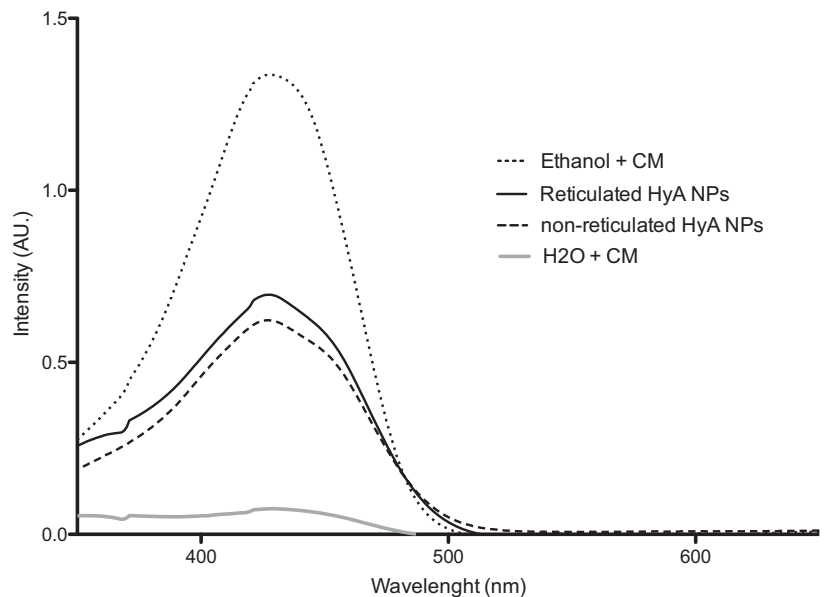

Figure 12. UV-Vis absorbance spectrum of curcumin at a $30 \mathrm{~mm}$ concentration solubilized in different solvents and in the presence of HyA-AT and HyA-AT-DPDPB nanogel.

curcumin concentration of $30 \mathrm{~mm}$-precipitation of the (presumably) non-incorporated curcumin being observed. The nanogel dispersion developed a bright yellow colour characteristic of solubilized curcumin. The same dilution of the stock-solution of curcumin was applied in an ethanol control solution, illustrative of the maximum curcumin loading absorption. The absorption at $428 \mathrm{~nm}$ confirm the curcumin loading in both the reticulated and non-reticulated nanogel samples, as seen in Figure 12, reaching concentrations of 15.63 and $13.94 \mathrm{~mm}$, respectively. Similar results were obtained by researchers with PLGA nanogel. ${ }^{[34]}$

Simvastatin loading was performed in a similar way. An ethanolic stock solution of simvastatin was added to $1.0 \mathrm{mg}$ mL nanogel dispersion, leading to a final simvastatin concentration of $71.7 \mu \mathrm{M}$. In Figure 13, the characteristic absorption of simvastatin at 238 and $247 \mathrm{~nm}$ is detected;

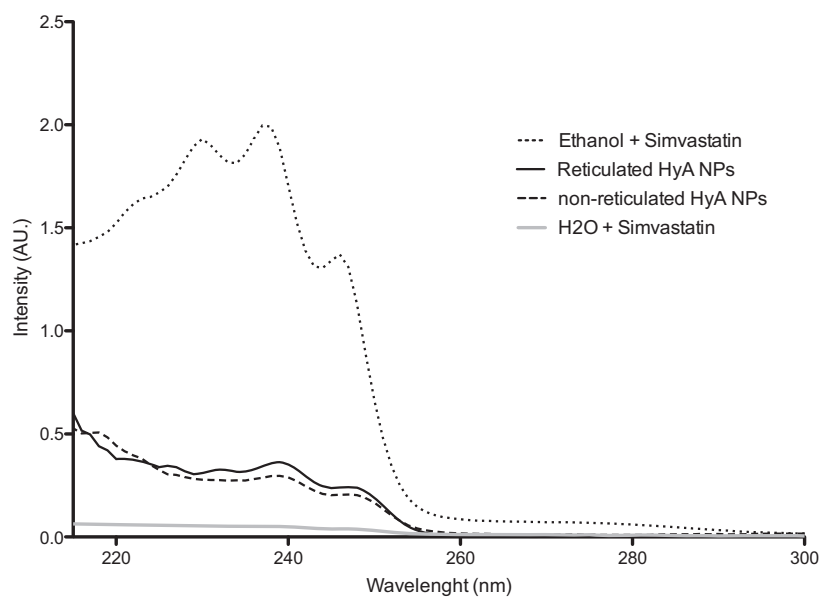

Figure 13. UV-Vis absorbance spectrum of simvastatin at a $71.7 \mu \mathrm{M}$ concentration in different solvents and in the presence of HyA-AT and HyA-AT-DPDPB nanogel. 
Table 1. DLS results of the hydrodynamic particles size (diameter-nm) of the HyA-AT and HyA-AT-DPDPB nanogel, before and after the drug incorporation. Here is also described the amount of drug loaded and drug loading efficiency of the nanogels.

\begin{tabular}{lccrr}
\hline Sample & Drug loaded & Drug loading & Encapsulation Efficiency & Size (SD) \\
\hline HyA-AT & - & & $86.76 \pm 2.063 \mathrm{~nm}$ \\
HyA-AT-DPDPB & & & & $122.2 \pm 40.70 \mathrm{~nm}$ \\
HyA-AT & Curcumin & $13.94 \mathrm{~mm}$ & $40.46 \pm 1.5 \%$ & $175.8 \pm 22.15 \mathrm{~nm}$ \\
HyA-AT-DPDPB & & $15.63 \mathrm{~mm}^{-1}$ & $52.1 \pm 1.8 \%$ & $159.3 \pm 6.725 \mathrm{~nm}$ \\
HyA-AT & Simvastatin & $11.85 \mu \mathrm{g} \mathrm{mL}^{-1}$ & $44.63 \pm 0.9 \%$ & $148.2 \pm 3.563 \mathrm{~nm}$ \\
HyA-AT-DPDPB & & $13.39 \mu \mathrm{g} \mathrm{mL}^{-1}$ & $39.5 \pm 1.2 \%$ & $150.3 \pm 18.59 \mathrm{~nm}$
\end{tabular}

settling the entrapment of the hydrophobic drug by the reticulated and non-reticulated nanogels, yielding estimated amounts of soluble simvastatin of 11.85 and $13.39 \mu \mathrm{g}$ $\mathrm{mL}^{-1}$, respectively. Similar entrapment concentrations were obtained in other works. ${ }^{[25,35,36]}$

The effect of the drug incorporation in the size of the nanogel was assessed by DLS analysis (Table 1). The swelling of the non-reticulated nanogels is noticeable, as also observed with similar materials. ${ }^{[29,37]}$ As expected, the reticulated nanogel exhibited higher size stability and was not significantly affected by the drug loading.

\section{Conclusion}

The synthesis of a thiolated hyaluronic acid conjugate that self-assembles into nanosized structures was achieved in a versatile, easy and reproducible manner. The nanogel presented long-term stability in solution and a fairly low critical aggregation concentration, which envisages good behaviour upon dilution, such as in vivo administration. The nanogel was successfully reticulated by dissulfide bond with a homofunctional crosslinker that linked the thiolated hydrophobic chains between them. Further, with the effective encapsulation of hydrophobic drugs suggest that both nanogels embody good vector systems for drug release and may exhibit redox sensitive trigger burst drug release.

Acknowledgements: The authors would like to acknowledge the support of FCT for the PhD grant reference SFRH/BD/61516/2009.

Received: March 18, 2014; Revised: May 23, 2014; Published online: August 4, 2014; DOI: 10.1002/mabi.201400135

[1] K. Y. Choi, G. Saravanakumar, J. H. Park, K. Park, Colloids Surf. B, Biointerfaces 2012, 99, 82.

[2] K. Y. Choi, K. H. Min, J. H. Na, K. Choi, K. Kim, J. H. Park, I. C. Kwon, S. Y. Jeong, J. Mater. Chem. 2009, 19, 4102.
[3] S. Ekici, P. Ilgin, S. Butun, N. Sahiner, Carbohydr. Polym. 2011, 84, 1306.

[4] F. Li, B. C. Bae, K. Na, Bioconjug. Chem. 2010, 21, 1312.

[5] A. Fakhari, C. Berkland, Acta Biomater. 2013, 9, 7081.

[6] E. J. Oh, K. Park, K. S. Kim, J. Kim, J.-A. Yang, J.-H. Kong, M. Y. Lee, A. S. Hoffman, S. K. Hahn, J. Controlled Release 2010, $141,2$.

[7] C. Cheng, E. Khoshdel, K. L. Wooley, Macromolecules 2007, 40, 2289.

[8] Y.-L. Li, L. Zhu, Z. Liu, R. Cheng, F. Meng, J.-H. Cui, S.-J. Ji, Z. Zhong, Angew. Chem. Int. Ed. 2009, 48, 9914.

[9] M. Talelli, M. Iman, A. K. Varkouhi, C. J. Rijcken, R. M. Schiffelers, T. Etrych, K. Ulbrich, C. F. van Nostrum, T. Lammers, G. Storm, W. E. Hennink, Biomaterials 2010, 31 , 7797.

[10] Y. Xu, F. Meng, R. Cheng, Z. Zhong, Macromol. Biosci. 2009, 9, 1254.

[11] J. Li, M. Huo, J. Wang, J. Zhou, J. M. Mohammad, Y. Zhang, O. Zhu, A. Y. Waddad, O. Zhang, Biomaterials 2012, 33, 2310.

[12] S. Ganesh, A. K. Iyer, D. V. Morrissey, M. M. Amiji, Biomaterials 2013, 34, 3489.

[13] Y. Liu, J. Sun, W. Cao, J. Yang, H. Lian, X. Li, Y. Sun, Y. Wang, S. Wang, Z. He, Int. J. Pharm. 2011, 421, 160.

[14] Y. Shen, O. Li, J. Tu, J. Zhu, Carbohydr. Polym. 2009, 77, 95.

[15] M. H. M. Oudshoorn, R. Rissmann, J. A. Bouwstra, W. E. Hennink, Polymer 2007, 48, 1915.

[16] M. von Smoluchowski, Ann. Phys. 1906, 326, 756.

[17] K. D. Wittrup, G. L. Verdine, "Protein Engineering for Therapeutics," Elsevier Science, USA 2012, DOI: 10.1016/ B978-0-12-396962-0.00013-6.

[18] G. T. Hermanson, “Bioconjugate Techniques," Elsevier Science, USA 2010, ISBN: 978-0-12-370501-3.

[19] N. C. f. B. Information, "SID: 54454."

[20] F. S. Palumbo, G. Pitarresi, D. Mandracchia, G. Tripodo, G. Giammona, Carbohydr. Polym. 2006, 66, 379.

[21] M. Bodnár, L. Daróczi, G. Batta, J. Bakó, J. Hartmann, J. Borbély, Colloid Polym. Sci. 2009, 287, 991.

[22] Y.-J. Jin, U. Termsarasab, S.-H. Ko, J.-S. Shim, S. Chong, S.-J. Chung, C.-K. Shim, H.-J. Cho, D.-D. Kim, Pharm. Res. 2012, 29, 3443.

[23] G. B. Dutt, S. Doraiswamy, J. Chem. Phys. 1992, 96, 2475.

[24] M. M. G. Krishna, J. Phys. Chem. A 1999, 103, 3589.

[25] J. Yao, L. Zhang, J. Zhou, H. Liu, O. Zhang, Mol. Pharm. 2013, 10, 1080.

[26] Y. Zhang, M. Huo, J. Zhou, D. Yu, Y. Wu, Carbohydr. Polym. 2009, 77, 231. 
[27] C. Goncalves, Y. Lalatonne, L. Melro, G. Badino, M. F. M. Ferreira, L. David, C. F. G. C. Geraldes, L. Motte, J. A. Martins, F. M. Gama, J Mater. Chem. B 2013, 1, 5853.

[28] S. Mahor, E. Collin, B. C. Dash, A. Pandit, Curr. Drug Delivery 2011, 8, 354.

[29] Y. H. Tao, J. Xu, M. O. Chen, H. Y. Bai, X. Y. Liu, Carbohydr. Polym. 2012, 88, 118.

[30] H. Salman, M. Bergman, M. Djaldetti, H. Bessler, Biomed. Pharmacother. =Biomed. Pharmacother. 2008, 62, 41.

[31] M. K. Jain, P. M. Ridker, Nat. Rev. Drug Discovery 2005, 4, 977.

[32] B. Kwak, F. Mulhaupt, S. Myit, F. Mach, Nat. Med. 2000, 6, 1399.
[33] S. Manju, K. Sreenivasan, J. Colloid Interface Sci. 2011, 359, 318.

[34] S. Doggui, J. K. Sahni, M. Arseneault, L. Dao, C. Ramassamy, J. Alzheimer's Dis. 2012, 30, 377.

[35] S. D. Nath, N. T. Linh, A. Sadiasa, B. T. Lee, J. Biomater. Appl. 2013, 28, 1151.

[36] G. Saravanakumar, K. Y. Choi, H. Y. Yoon, K. Kim, J. H. Park, I. C. Kwon, K. Park, Int. J. Pharm. 2010, 394, 154.

[37] A. K. Yadav, A. Agarwal, G. Rai, P. Mishra, S. Jain, A. K. Mishra, H. Agrawal, G. P. Agrawal, Drug Delivery 2010, 17, 561. 